\title{
Análises fisiológicas e morfoanatômicas de Cenostigma macrophyllum Tul. (Fabaceae) submetida a diferentes concentrações de glifosato
}

Objetivou-se identificar os efeitos do glifosato em Cenostigma macrophyllum, a fim de indicar possíveis características bioindicadoras da presença do herbicida em plantas. 0 estudo fo realizado em casa de vegetação. $O$ experimento consistiu em 7 tratamentos, com 4 repetição cada, incluindo 6 diferentes doses do herbicida: $25,50,100,200,400,800 \mathrm{~g}$ i.a. ha ${ }^{-1}$ e o controle. As avaliações foram realizadas no folíolo da extremidade da folha da região mediana de cada planta. Foram determinados os valores de fotossíntese (A), trocas gasosas (E), transpiração (gs) e relação entre a concentração interna (Ci) e externa $(\mathrm{Ca})$ de $\mathrm{CO}_{2}(\mathrm{Ci} / \mathrm{Ca})$. A mesma área foi utilizada para avaliação de fluorescência da clorofila $a$. Foi determinada a fluorescência inicial ( $\mathrm{FO}$ ), fluorescência máxima $(\mathrm{Fm})$, rendimento quântico potencial $(\mathrm{Fv} / \mathrm{Fm})$, rendimento quântico efetivo ( $\Delta \mathrm{F} / \mathrm{Fm}$ ), dissipação não fotoquímica (NPO) e taxa aparente de transporte de elétrons ( $(\mathrm{ETR})$. As folhas avaliadas foram coletadas para avaliação da concentração de pigmentos cloroplastídicos, avaliação da permeabilidade de membranas e análises morfoanatômicas. Houve redução As folhas avaliadas foram coletadas para avaliação da concentração de pigmentos cloroplastídicos, avaliação da permeabilidade de membranas e análises morfoanatômicas. Houve redução
nos valores de $\mathrm{A}$, gs e $\mathrm{E}$ e aumento de $\mathrm{Ci} / \mathrm{Ca}$, indicando acúmulo de $\mathrm{CO}_{2}$ na cavidade subestomática. O glifosato não provocou danos significativos nos parâmetros de fluorescência da clorofila $a$, na degradação da membrana, bem como no conteúdo de pigmentos cloroplastídicos. Análises anatômicas indicaram alterações na intensidade de emissão de autofluorescência da clorofila a. Houve redução na espessura da epiderme adaxial, nos parênquimas paliçádico e esponjoso e redução na epiderme abaxial, diferindo significativamente do controle já na primeira dose observada. Os folíolos apresentaram clorose e necrose, além do brotamento de folhas retorcidas na maior dose. A redução de gs e consequente redução de E e A, podem indicar ação do herbicida nas células guarda, provocando o fechamento dos estômatos, no entanto o aumento na relação $\mathrm{Ci} / \mathrm{Ca}$ indicam que esses danos não ocorreram somente nos estômatos, provavelmente houve uma diminuição da difusão de $\mathrm{CO}_{2}$ no mesofilo ou até mesmo danos ou diminuição da quantidade da enzima Rubisco, responsável pela fixação do $\mathrm{CO}_{2}$ no $\mathrm{Ciclo}_{\text {a }}$ de Calvin. A redução dos tecidos foliares pode ter contribuído com a deficiência de difusão de $\mathrm{CO}_{2}$ no mesofilo. As respostas morfoanatômicas evidenciaram danos à clorofila, podendo ser utilizado como um alerta inicial de possíveis danos futuros. Os parâmetros avaliados em que foi possível perceber o efeito do herbicida, indicados em caso de biomonitoramento com a espécie estudada, foram: trocas gasosas, emissão de autofluorescência da clorofila e análises morfoanatômicas.

Palavras-chave: Agrotóxicos; Cerrado; Herbicidas; Caneleiro; Fotossíntese.

\section{Physiological and morphoanatomic analysis of Cenostigma macrophyllum Tul. (Fabaceae) submitted to different concentrations of glyphosate}

The aim was to identify the effects of glyphosate on Cenostigma macrophyllum in order to indicate possible bioindicating characteristics of the presence of the herbicide in plants. The study was conducted in a green house. The experiment consisted of 7 treatments, with 4 repetitions each, including 6 different doses of the herbicide: $25,50,100,200,400,800 \mathrm{~g}$ i.a. ha ${ }^{-1}$ and the control. The evaluations were performed on the leaf tip foliar of the median region of each plant. The values of photosynthesis (A), gas exchange (E), perspiration (gs) and the relation between internal (Ci) and external $(\mathrm{Ca})$ concentration of $\mathrm{CO}_{2}(\mathrm{Ci} / \mathrm{Ca}$ ) were determined. The same area was used to evaluate the fluorescence of chlorophyll $a$. The initial fluorescence ( $\mathrm{FO}$ ), maximum fluorescence $(\mathrm{Fm})$, potential quantum yield $(\mathrm{Fv} / \mathrm{Fm})$, effective quantum yield $\left(\Delta \mathrm{F} / \mathrm{Fm} \mathrm{m}^{\prime}\right)$, non-photochemical dissipation $(\mathrm{NPQ})$ and apparent electron transport rate $(\mathrm{ETR})$ were determined. The sheets evaluated were collected to evaluate the concentration of chloroplastidic pigments, membrane permeability evaluation and morph anatomical analysis. There was a reduction in $\mathrm{A}$, gs and $\mathrm{E}$ values and an increase in $\mathrm{Ci} / \mathrm{Ca}$, indicating $\mathrm{CO}_{2}$ accumulation in the sub stomatic cavity. Glyphosate did not cause significant damage to the chlorophyll $a$ fluorescence parameters, membrane degradation, as well as chloroplastid pigment content. Anatomical analysis indicated changes in the autofluorescence emission intensity of chlorophyll $a$. There was a reduction in the thickness of the adaxial epidermis, in the palisadic and spongy parenchymes and a reduction in the abaxial epidermis, differing significantly from the control in the first dose observed. The leaflets presented chlorosis and necrosis, besides the sprouting of twisted leaves in the highest dose. The reduction of gs and consequent reduction of $\mathrm{E}$ and $\mathrm{A}$, may indicate the action of the herbicide in the guard cells, causing the closure of the stomas, however the increase in the $\mathrm{Ci} / \mathrm{Ca}$ ratio indicates that these damages did not occur only in the stomas, probably there was a decrease in the diffusion of $\mathrm{CO}_{2}$ in the mesophilus or even damage or decrease in the amount of the enzyme Rubisco, responsible for the fixation of $\mathrm{CO}_{2}$ in the $\mathrm{Calvin}_{\mathrm{C}} \mathrm{cll}$. The reduction of foliar tissues may have contributed to the deficiency of $\mathrm{CO}_{2}$ diffusion in mesophyll. Morphoanatomic responses have shown damage to chlorophyll and can be used as an early warning of possible future damage. The parameters evaluated in which it was possible to perceive the effect of the herbicide, indicated in case of biomonitoring with the studied species, were: gas exchange, chlorophyll autofluorescence emission and morphoanatomic analyses.

Keywords: Pesticides; Cerrado; Herbicides; Caneleiro; Photosynthesis.

Topic: Botânica Agrícola

Reviewed anonymously in the process of blind peer.
Received: 04/08/2020

Approved: 19/09/2020
Vanessa Ribeiro de Sousa Santos (iD Universidade Federal do Tocantins, Brasil http://lattes.cnpq.br/4288015295406608 http://orcid.org/0000-0002-0469-7939 vanessarss@mail.uft.edu.br

Ailton José Crispim Filho (iD

Universidade Federal de Goiás, Brasil

http://lattes.cnpq.br/9735629084160640

http://orcid.org/0000-0003-4813-3016

ailtonicf@gmail.com

Marinna Maciel Santana

Universidade Federal do Tocantins, Brasil

http://lattes.cnpq.br/3029295568848119

marinnasm@gmail.com

a

DOI: 10.6008/CBPC2179-6858.2020.005.0017

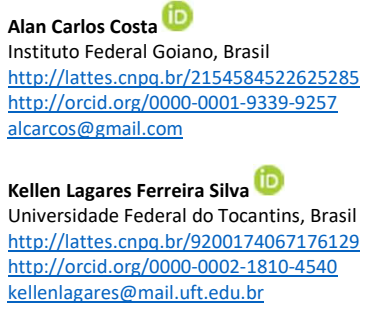

Referencing this:

SANTOS, V. R. S.; CRISPIM FILHO, A. J.; SANTANA, M. M.; COSTA, A. C.; SILVA, K. L. F.. Análises fisiológicas e morfoanatômicas de Cenostigma macrophyllum Tul. (Fabaceae) submetida a diferentes concentrações de glifosato. Revista Ibero Americana de Ciências Ambientais, v.11, n.5, p.159-173, 2020. DOI: http://doi.org/10.6008/CBPC21796858.2020.005.0017 


\section{INTRODUÇÃO}

O glifosato é o herbicida de maior participação no mercado mundial de herbicidas, e é o mais utilizado no Brasil, caracterizando-se pelo amplo espectro de ação e por não ser seletivo à cultura da soja. Existem mais de 90 marcas comerciais com esse ingrediente ativo no mundo. Apesar do glifosato ser citado como pouco tóxico, há evidências de efeitos deletérios no ambiente, principalmente devido à resistência adquirida por algumas espécies de ervas, após o uso prolongado do herbicida. Em diversos tipos de cultivo, o glifosato costuma ser pulverizado, sendo absorvido pela planta através de suas folhas e dos caulículos novos. A pulverização pode atingir plantas não-alvo por conta da deriva do herbicida.

Conforme Yamada et al. (2007), o herbicida é transportado por toda a planta, agindo nos vários sistemas enzimáticos, inibindo o metabolismo de aminoácidos. O glifosato é o único herbicida que atua diretamente sobre a enzima 5-enolpiruvil-chiquimato-3-fosfato-sintase (EPSPS), inibindo-a. Essa interação suprime a síntese dos aminoácidos aromáticos essenciais como a fenilalanina, tirosina e triptofano, os quais são precursores de outros produtos, como lignina, alcaloides, flavonoides e ácidos benzoicos. As plantas tratadas com glifosato morrem lentamente, em poucos dias ou semanas e, devido ao transporte por todo o sistema, nenhuma parte da planta sobrevive.

O biomonitoramento é uma das formas de avaliar os efeitos dos herbicidas no ambiente. Conforme um autor, biomonitoramento é o uso sistemático das respostas de organismos vivos para avaliar as mudanças ocorridas no ambiente, geralmente causadas por ações antropogênicas. O estudo da anatomia e fisiologia de plantas expostas a poluentes têm contribuído com informações sobre a qualidade do seu ambiente ou parte dele.

Mesmo atuando diretamente na inibição da enzima EPSPS, o glifosato pode acarretar outros sintomas nas plantas. No presente estudo, foram avaliadas respostas fisiológicas e morfoanatômicas de plântulas de Cenostigma macrophyllum, quando expostas a diferentes doses de glifosato, em condições controladas em casa de vegetação. O propósito desse trabalho foi identificar possíveis padrões de respostas da espécie estudada, a fim de indicar avaliações adequadas e características bioindicadoras da presença do glifosato em áreas atingidas por deriva.

\section{MATERIAIS E MÉTODOS}

\section{Caracterização da espécie estudada}

Cenostigma macrophyllum, conhecida popularmente como canela-de-velho, caneleira e cega facão (SILVA, 2004), é uma planta pioneira, de porte arbóreo arbustivo, pertencente à subfamília Caesalpinioideae (WARWICK et al., 2009), e quando adulta pode atingir até $20 \mathrm{~m}$ de altura. Pode ser encontrada em abundância na região do Cerrado e Caatinga (QUEIROZ, 2002; 1998) e é bastante utilizada na alimentação de animais e aproveitamento da madeira. Estudos farmacológicos do caule e folha indicam ação antiulcerogênica, antiinflamatória e antinociceptiva de C. macrophyllum (SILVA, 2004; SILVA et al., 2007), além de propriedades antioxidantes das substâncias fenólicas, que estão relacionadas à redução de doenças causadas por radicais 
livres (MOKBEL et al., 2006). A abundância dessa espécie é um fator importante a ser levado em consideração para sua utilização como bioindicadora da presença de glifosato em áreas próximas a monoculturas, que utilizam frequentemente esse herbicida e que possam ter sido afetadas em consequência da deriva.

\section{Condições de cultivo e delineamento experimental}

O estudo foi realizado em casa de vegetação do Laboratório de Ecofisiologia e Produtividade Vegetal do Instituto Federal Goiano, Campus Rio Verde, Goiás, Brasil, com temperatura e umidade controladas. A temperatura mínima registrada foi 23.9 ㅇ C e a máxima 29 으. A umidade relativa do ar variou entre $60.2 \%$ e $80.9 \%$

As sementes da espécie Cenostigma macrophyllum foram obtidas nas proximidades da TO 050, que liga o município de Porto Nacional a Palmas, ambos no estado do Tocantins, Brasil, em locais adjacentes a plantações de soja. Foram coletadas aproximadamente 200 sementes de diferentes matrizes, em torno de quinze. Inicialmente, as sementes foram plantadas em bandejas de plástico contendo areia, após germinadas foram transferidas para vasos de polietileno com $3 \mathrm{Kg}$ de substrato constituído de uma parte de areia e duas partes de solo de Cerrado. Para prevenir possíveis deficiências nutricionais que pudessem interferir nas respostas dos tratamentos, foi aplicada solução nutritiva de Hoagland et al. (1950), 60 dias após a germinação.

O experimento consistiu em 7 tratamentos, com 4 repetições cada, incluindo 6 diferentes doses do herbicida Glifosato (Roundup Transorb, N-(phosphonomethyl) glycine, Sal de Potássio de Glifosato 588 g/L (480 g/L equivalente ácido), importado pela Monsanto do Brasil Ltda.: 25, 50, 100, 200, 400, $800 \mathrm{~g}$ i.a. ha-1 e o controle (0). As doses do herbicida foram aplicadas 4 meses após a germinação. Para aplicar o herbicida foi utilizado um pulverizador costal, com pressão constante mantida por $\mathrm{CO}_{2}$ comprimido munido de barra, com quatro pontas de pulverização. A pressão de serviço utilizada foi de $\mathrm{kgf} \cdot \mathrm{cm}^{-2}$, proporcionando um volume de calda de $200 \mathrm{~L} \mathrm{ha}^{-1}$. O herbicida foi pulverizado fora da casa de vegetação, uma só vez, nas quatro repetições de cada dose, ao mesmo tempo. Após aproximadamente 01:30h, os vasos foram transportados para a casa de vegetação e acondicionados aleatoriamente.

\section{Trocas gasosas}

Para avaliação das trocas gasosas foram realizadas cinco medições, 24, 72, 216, 288 e 360 horas após a pulverização do herbicida. Estas avaliações foram realizadas no folíolo da extremidade da folha da região mediana de cada planta. Além das trocas gasosas a mesma área foi utilizada para avaliação de fluorescência da clorofila $a$.

As taxas fotossintéticas $\left(A, \mu \mathrm{mol} \mathrm{m}^{-2} \mathrm{~s}^{-1}\right)$ e transpiratória $\left(E, \mathrm{mmol} \mathrm{m}^{-2} \mathrm{~s}^{-1}\right)$, a condutância estomática ( $\mathbf{g}_{s}, \mathrm{~mol} \mathrm{H} \mathrm{O} \mathrm{m}^{-2} \mathrm{~s}^{-1}$ ) e a relação entre a concentração interna (Ci) e externa (Ca) de $\mathrm{CO}_{2}(\mathrm{Ci} / \mathrm{Ca}$ ), foram obtidas por meio de um sistema de medição de trocas gasosas portátil LI-6400XTR (Licor/Nebrasca). As mensurações foram feitas sob concentração de $\mathrm{CO}_{2}$, temperatura e vapor de $\mathrm{H}_{2} \mathrm{O}$ do ambiente do local de estudo, controlados, sendo o ar de referência homogeneizado em um galão de $20 \mathrm{~L}$ antes de alcançar a câmara foliar. 
Após o coeficiente que combina as variações de gás carbônico $\left(\Delta \mathrm{CO}_{2}\right)$, água $\left(\Delta \mathrm{H}_{2} \mathrm{O}\right)$ e fluxo de $\operatorname{ar}\left(\Delta \mu_{\mathrm{e}}\right)$ ter ficado abaixo de 1\%, foram realizados 10 registros por folha, um a cada 12 segundos, cuja média foi considerada uma medida.

\section{Fluorescência da clorofila $a$}

Para avaliação de fluorescência da clorofila $a$ foram realizadas seis medições, 24, 72, 144, 216, 288 e 360 horas após a pulverização do herbicida.

A fluorescência da clorofila $a$ foi avaliada utilizando um fluorômetro portátil modulado, modelo MINIPAM (Walz, Effeltrich, Germany), equipado com pinça especial para suporte da folha, modelo 2030-B (BILGER et al., 1995; RASCHER et al., 2000). Foi determinada a fluorescência inicial (F0), fluorescência máxima (Fm), rendimento quântico potencial (Fv/Fm = Fluorescência variável/Fluorescência máxima), rendimento quântico efetivo $(\boldsymbol{\Delta} \mathbf{F} / \mathbf{F m}$ '), dissipação não fotoquímica (NPQ) e taxa aparente de transporte de elétrons (ETR). O rendimento quântico potencial do fotossistema II (VAN KOOTEN et al., 1990) foi calculado após 30 minutos de adaptação ao escuro utilizando a equação $\mathrm{Fv} / \mathrm{Fm}=(\mathrm{Fm}-\mathrm{FO}) / \mathrm{Fm}$; em que $\mathrm{F} 0$ é o rendimento da fluorescência mínima, excitado pela luz vermelha modulada de baixa intensidade (0,03 mmol m-2 s-1), e Fm é a fluorescência máxima obtida pela aplicação do pulso de $0,8 \mathrm{~s}$ de luz actínica saturante ( $>6000 \mu \mathrm{mol}$ m-2 s-1). O rendimento quântico efetivo do fotossistema II (GENTY et al., 1989) foi determinado por meio da sobreposição do pulso de saturação em folhas previamente adaptadas à luz ambiente, sendo calculado como $\Delta F / F m^{\prime}=\left(F m^{\prime}-F\right) / F m^{\prime} ;$ em que $F$ é o rendimento da fluorescência máxima durante o pulso de saturação. $O$ $\Delta \mathrm{F} / \mathrm{Fm}^{\prime}$ foi utilizado para estimar a taxa aparente de transporte de elétrons (ETR), de acordo com (BILGER et al., 1995), mediante o uso da equação $E T R=\Delta F / F m^{\prime} \times D F F \times 0,5 \times 0,84$, em que DFF é a densidade de fluxo de

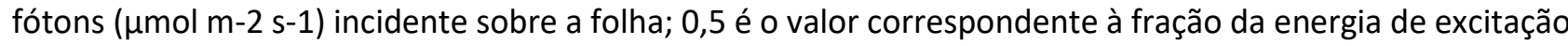
distribuída para o FSII (LAISK et al., 1996) e 0,84 é o valor correspondente à fração de luz incidente que é absorvida pelas folhas (EHLERINGER, 1981). O coeficiente de extinção não fotoquímica de Stern-Volmer foi calculado como NPQ $=\left(F m-F m^{\prime}\right) / F m^{\prime}(B I L G E R$ et al., 1990).

\section{Concentração de pigmentos cloroplastídicos}

O conteúdo de pigmentos cloroplastídicos foi determinado ao final, após 360 horas, por meio da extração com dimetilsulfóxido (DMSO), mediante ajustes da metodologia descrita por Kuki et al. (2005). Foram coletados, de cada repetição, três discos foliares utilizando um furador de metal de $5 \mathrm{~mm}$ de diâmetro, evitando-se a nervura central. Os discos foram incubados em frascos de vidro protegidos da luz por papel alumínio, contendo $5 \mathrm{~mL}$ de $\mathrm{DMSO}$ saturado $\mathrm{com} \mathrm{CaCO}_{3}$. As amostras foram levadas ao banho-maria à temperatura de $65^{\circ} \mathrm{C}$ por 24 horas. Em seguida foram realizadas as leituras em espectrofotômetro UV-VIS, modelo Evolution 60S (Thermo Fisher Scientific, Madison - USA). Os comprimentos de onda, as equações e os cálculos para a determinação do conteúdo de clorofilas $a(480 \mathrm{~nm}), b(649 \mathrm{~nm})$ e carotenoides (665 nm) foram conforme metodologia de (WELLBURN, 1994). A degradação da clorofila foi avaliada por espectrofotometria, adotando o índice de feofitinização ( $\left(\mathrm{F}=\mathrm{A}_{435} / \mathrm{A}_{415}\right)$, segundo Ronen et al. (1984). 


\section{Avaliação da permeabilidade de membranas}

A permeabilidade de membrana foi determinada após 360 horas, por meio da taxa de liberação de eletrólitos (TLE) segundo adaptação da metodologia descrita por Vasquez-Tello et al. (1989) e Pimentel et al. (2002). Foram coletados 15 discos foliares, de cinco mm de diâmetro, em cada repetição, da folha avaliada, preservando o folíolo avaliado para os cortes de anatomia. Os discos foram lavados previamente com água e então submersos em $30 \mathrm{~mL}$ de água deionizada, em frascos âmbar, por um período de 24 horas à temperatura ambiente. Após este período, foi mensurado a condutividade livre ( $\mathrm{CL}, \mu \mathrm{S} / \mathrm{cm})$, utilizando um condutivímetro portátil CD-850. Posteriormente, os mesmos frascos foram colocados em estufa por uma hora sob temperatura de $100{ }^{\circ} \mathrm{C}$ e, após o resfriamento em temperatura ambiente, foi medida a condutividade total (CT, $\mu \mathrm{S} / \mathrm{cm})$. Para evitar o erro nos resultados, o sensor foi lavado entre cada leitura com água deionizada. A taxa de liberação de eletrólitos foi obtida utilizando a fórmula TLE (\%) = CL/CT x 100 .

\section{Análises anatômicas}

As observações por microscopia de fluorescência foram realizadas no Laboratório de Anatomia Vegetal do Instituto Federal Goiano, Campus Rio Verde, Goiás, Brasil, com um microscópio Olympus BX61 ICAL, por meio de excitação azul (450-490nm), em secções frescas, cortadas com um micrótomo de mesa e imediatamente fotografadas para evitar a degradação da clorofila.

As amostras foram coletadas 360 horas após a aplicação do herbicida. Foram coletados os folíolos completamente expandidos utilizados nas avaliações de trocas gasosas e fluorescência da clorofila $a$, e selecionados cortes da região mediana, mais próximos da borda, evitando a nervura. A região da folha adjacente à coletada para análise de fluorescência, contendo a nervura principal, foi coletada para microscopia de luz.

As amostras para microscopia de luz foram fixadas em solução Glutaraldeído 1\% em tampão fosfato 0,2M, pH 7,2 (KARNOVSKY, 1965) modificado (KRAUS et al., 1997) durante 24 horas. Após esse período foram efetuadas três lavagens de 15 minutos em tampão fosfato 0,2M, pH 7,2 e realizada e desidratação em série etílica crescente até o álcool 70\%, no qual foi possível armazenar e conservar o material. Ao fim desta etapa, as amostras foram levadas para o laboratório de anatomia vegetal da Universidade Federal do Tocantins, Campus de Porto Nacional, Tocantins, onde foram desidratadas em um intervalo de tempo de 1 hora para cada troca, em série etílica e butílica (80, 90 e 100\%, etílico butílico (3:1), etílico butílico (1:1), etílico butílico (1:3) e butílico puro) permanecendo 'over night' em álcool butílico + parafina (1:1), e posteriormente submetidas a duas trocas de parafina por 1 hora cada. Após infiltração, as amostras foram emblocadas (parafina + cera de abelha 8\%), seguindo orientação do plano de corte (transversal). Após o resfriamento, os blocos foram colocados em suporte de madeira, onde foram confeccionados quatro blocos para cada tratamento totalizando 28 blocos.

Para a caracterização anatômica foram feitos cortes transversais em micrótomo rotativo semimotorizado (RM2245-Leica), a 12 $\mu$ m de espessura e aderidos à lâmina com adesivo de Haupt (1930). Foram 
confeccionadas cinco lâminas, com aproximadamente 10 cortes para cada bloco. Posteriormente, os cortes foram desparafinizados em série xilólica, hidratados em série etílica e corados em safranina $1 \%$ e azul de astra, por 20 min (GERLACH, 1984). Em seguida, as lâminas foram lavadas em água destilada e desidratadas em série etílica (30\%, 50\%,70\%, 85\%, 95\% e 100\%), para posteriormente serem submetidas a série xilólica e montadas com bálsamo do Canadá, entre lâmina e lamínula. Em cada lâmina foram selecionados aleatoriamente três cortes. As imagens foram capturadas pelo microscópio óptico Leica DM 500, com câmera Leica ICC50 HD acoplada. A morfometria foliar foi feita com auxílio do software de análise de imagens ANATI QUANTI, versão 2.0 para Windows (AGUIAR et al., 2007).

\section{Estatística}

Os dados foram submetidos à análise de variância (ANOVA), as médias foram comparadas pelo teste de Tukey $(p<0,05)$ e quando necessários, modelos de regressão foram ajustados. As análises estatísticas foram realizadas no software $R$ ( $R$ CORE TEAM, 2015).

\section{RESULTADOS}

\section{Efeito do glifosato sobre as trocas gasosas}

As análises de trocas gasosas em Cenostigma macrophyllum apresentaram um efeito negativo e progressivo em relação ao aumento das doses e das horas após a exposição das plantas ao glifosato (Figura 1). Diferenças significativas na fotossíntese $(\mathbf{A})$, condutância estomática $\left(\mathbf{g}_{\mathbf{s}}\right)$ e taxa transpiratória $(\mathbf{E})$ foram observadas entre 216 e 360 horas, após a aplicação do herbicida (Tabela 1). Ao compararmos as leituras destes parâmetros, na dose $800 \mathrm{~g}$ i.a. ha-1, 360 horas após a aplicação, a fotossíntese (A) (Figura 1-A) ficou reduzida em aproximadamente $72 \%$ e a condutância estomática $\left(\mathbf{g}_{\mathrm{s}}\right)$ e taxa transpiratória (E) (Figuras 1-B e 1-C) foram reduzidas em $64 \%$ e $59 \%$ respectivamente, em relação ao controle. A relação Ci/Ca oscilou levemente nas diferentes doses, apresentando uma tendência de aumento 288 horas após a aplicação (Figura 1-D).
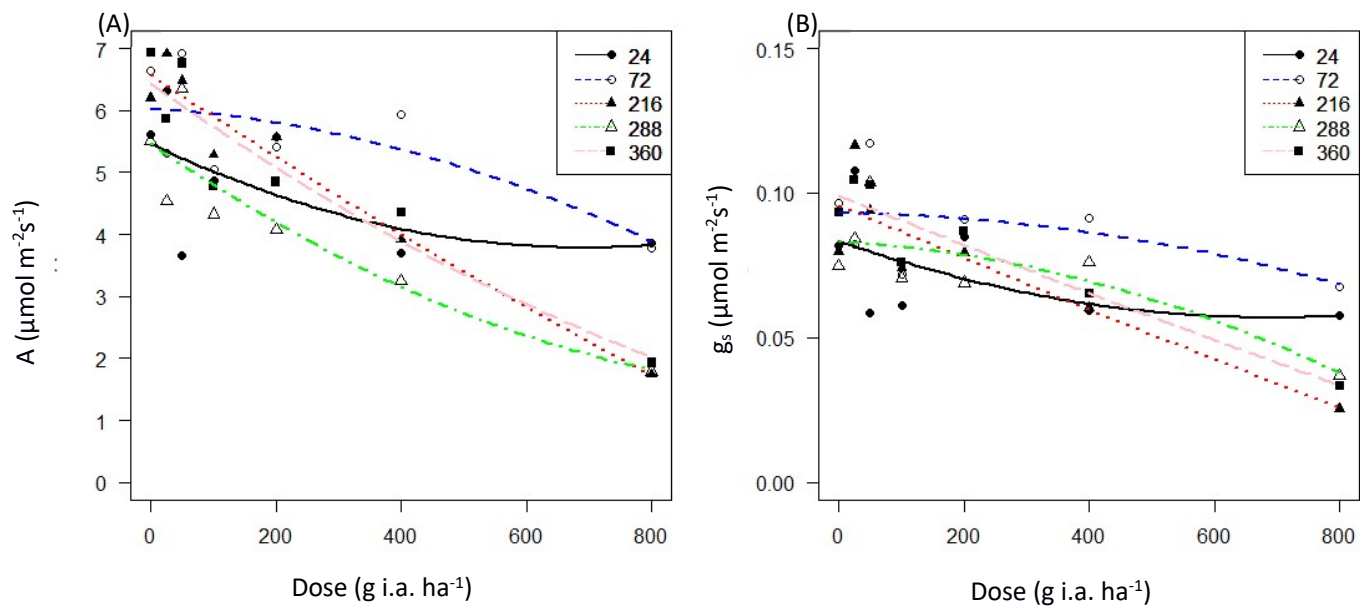

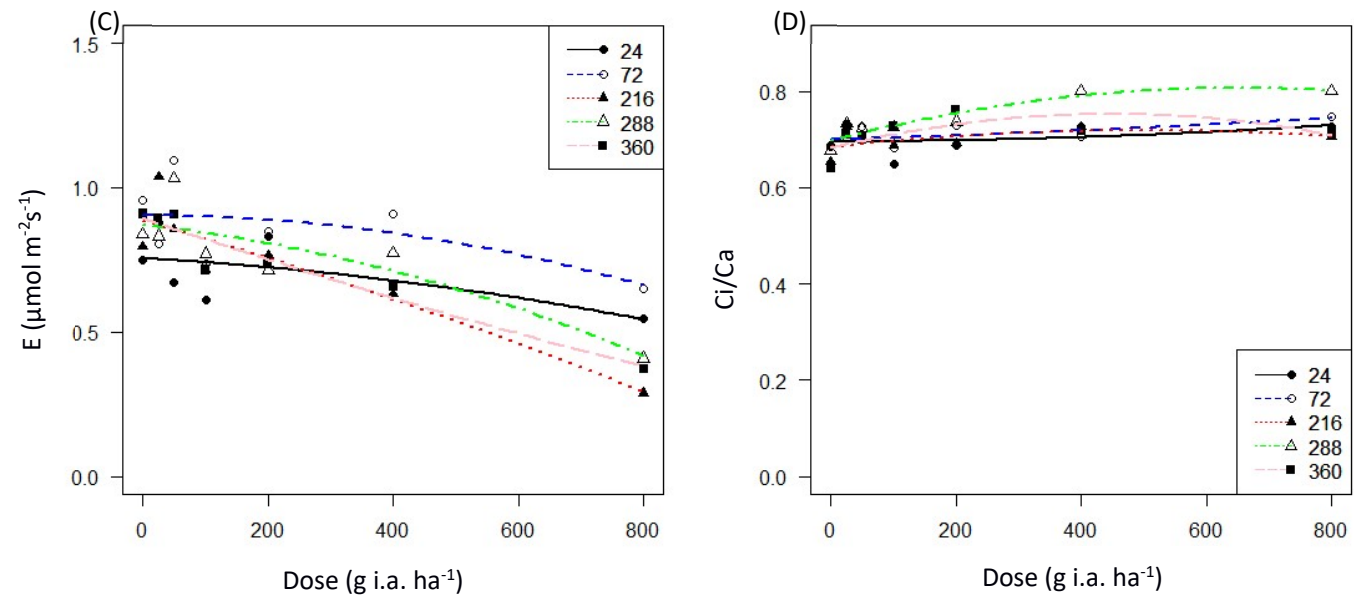

Figura 1: A: Taxa fotossintética - (A); B: condutância estomática - (gs); C: taxa transpiratória - (E); D: relação entre a concentração interna (Ci) e externa $(\mathbf{C a})$ de $\mathrm{CO}_{2}$ no mesofilo - $(\mathbf{C i} / \mathbf{C a})$; em plantas de $C$. macrophyllum submetidas a diferentes concentrações de glifosato, diferentes horas após a aplicação.

Tabela 1: Equações de ajuste de regressão para Taxa fotossintética - A, condutância estomática - $\mathbf{g s}$, taxa transpiratória - E e relação entre a concentração interna e externa de $\mathrm{CO}_{2}$ no mesofilo - $\mathbf{C i} / \mathbf{C a}$, em plantas de Cenostigma macrophyllum submetidas a diferentes concentrações de glifosato, em diferentes horas após a aplicação. Referente à Figura 1.

\begin{tabular}{|c|c|c|c|}
\hline Características & Unidade & Equações Ajustadas & $\mathrm{R}^{2}$ \\
\hline $\bar{A}$ & 24 horas após aplicação & $\bar{Y}=5.461 e+00-4.827 e-03 x+3.474 e-06 x^{2}$ & $0.03215^{\mathrm{ns}}$ \\
\hline A & 72 horas após aplicação & $\bar{Y}=6.030 e+00-6.169 e-04 x-2.577 e-06 x^{2}$ & $0.3194^{\text {ns }}$ \\
\hline A & 216 horas após aplicação & $\bar{Y}=6.573 e+00-6.835 e-03 x+9.696 e-07 x^{2}$ & $0.9265^{*}$ \\
\hline A & 288 horas após aplicação & $\bar{Y}=5.466 e+00-6.984 e-03 x+3.009 e-06 x^{2}$ & $0.7343^{*}$ \\
\hline A & 360 horas após aplicação & $\bar{Y}=6.436 e+00-7.231 e-03 x+2.138 e-06 x^{2}$ & $0.8249^{*}$ \\
\hline$g_{s}$ & 24 horas após aplicação & $\bar{Y}=8.354 e-02-7.688 e-05 x+5.549 e-08 x^{2}$ & $-0.07829^{n s}$ \\
\hline$g_{s}$ & 72 horas após aplicação & $\bar{Y}=9.304 e-02-2.724 e-06 x-3.503 e-08 x^{2}$ & $-0.06223^{n s}$ \\
\hline$g_{s}$ & 216 horas após aplicação & $\bar{Y}=9.568 e-02-9.211 e-05 x+5.543 e-09 x^{2}$ & $0.7032^{*}$ \\
\hline gs & 288 horas após aplicação & $\bar{Y}=8.307 e-02-1.129 e-05 x-5.676 e-08 x^{2}$ & $0.5147^{n s}$ \\
\hline$g_{s}$ & 360 horas após aplicação & $\bar{Y}=9.914 e-02-8.709 e-05 x+6.359 e-09 x^{2}$ & $0.8464^{*}$ \\
\hline$E$ & 24 horas após aplicação & $\bar{Y}=7.558 e-01-1.237 e-04 x-1.768 e-07 x^{2}$ & $0.1086^{\mathrm{ns}}$ \\
\hline E & 72 horas após aplicação & $\bar{Y}=9.042 e-01-3.522 e-06 x-3.750 e-07 x^{2}$ & $0.05377^{\mathrm{ns}}$ \\
\hline E & 216 horas após aplicação & $\bar{Y}=8.843 e-01-6.136 e-04 x-1.586 e-07 x^{2}$ & $0.7744^{*}$ \\
\hline $\mathrm{E}$ & 288 horas após aplicação & $\bar{Y}=8.703 e-01-2.332 e-04 x-4.143 e-07 x^{2}$ & $0.6413^{*}$ \\
\hline E & 360 horas após aplicação & $\bar{Y}=8.943 e-01-7.411 e-04 x+1.239 e-07 x^{2}$ & $0.8895^{*}$ \\
\hline $\mathrm{Ci} / \mathrm{Ca}$ & 24 horas após aplicação & $\bar{Y}=6.960 e-01+6.020 e-07 x+5.211 e-08 x^{2}$ & $-0.2447^{n s}$ \\
\hline $\mathrm{Ci} / \mathrm{Ca}$ & 72 horas após aplicação & $\bar{Y}=6.999 e-01+3.798 e-05 x+2.310 e-08 x^{2}$ & $0.2026^{\mathrm{ns}}$ \\
\hline $\mathrm{Ci} / \mathrm{Ca}$ & 216 horas após aplicação & $\bar{Y}=6.843 e-01+1.377 e-04 x-1.369 e-07 x^{2}$ & $-0.1521^{\mathrm{ns}}$ \\
\hline $\mathrm{Ci} / \mathrm{Ca}$ & 288 horas após aplicação & $\bar{Y}=6.989 e-01+3.328 e-04 x-2.558 e-07 x^{2}$ & $0.7887^{*}$ \\
\hline $\mathrm{Ci} / \mathrm{Ca}$ & 360 horas após aplicação & $\bar{Y}=6.825 e-01+3.147 e-04 x-3.521 e-07 x^{2}$ & $0.1608^{\text {ns }}$ \\
\hline
\end{tabular}

$\left({ }^{*}\right)$ Significativo e $\left({ }^{\text {ns }}\right)$ não significativo, $p<0,05$

\section{Efeito do glifosato sobre a fluorescência da clorofila a conteúdo de pigmentos cloroplastídicos e sobre permeabilidade de membranas}

O glifosato não afetou significativamente os parâmetros de fluorescência da clorofila $a$, o conteúdo de pigmentos cloroplastídicos, nem a permeabilidade de membranas. Observando-se os efeitos da fluorescência nas plantas expostas às doses 400 e $800 \mathrm{~g}$ i.a. ha-1 notou-se uma leve tendência de diminuição do rendimento quântico efetivo do fotossistema II e na taxa aparente de transporte de elétrons. Em contrapartida, foi observado um leve aumento no coeficiente de extinção não fotoquímica.

Não houve diminuição significativa de clorofila $a, b$ e carotenoides em decorrência do aumento do tempo ou dose do glifosato, nem alteração significativa na taxa de liberação de eletrólitos capaz de evidenciar danos sobre as membranas. 


\section{Efeitos do glifosato sobre a estrutura anatômica}

Na Figura 2 estão apresentados os resultados de fluorescência da clorofila obtidos na anatomia das plantas de Cenostigma macrophyllum. É possível observar um dano progressivo neste parâmetro, sendo esse mais evidente na dosagem de $800 \mathrm{~g}$ i.a. ha-1 ${ }^{-1}$ Esta resposta pode ser visualizada com maior detalhe na Figura 2-J, pois ao compararmos com a figura 2-A (com trole) ficou visível os danos causados pelo herbicida. No controle, observa-se nas células do parênquima, tanto paliçádico quanto esponjoso, uma coloração vermelha típica de plantas saudáveis da autofluorescência de clorofila, enquanto que em 2-J, é possível observar a mudança na coloração da emissão da fluorescência pela clorofila $a$, o que expressa que há um dano na clorofila.

Na figura 3 estão apresentados os resultados oriundos das análises anatômicas em microscopia de luz em plantas sadias e expostas a diferentes dosagens do glifosato. A estrutura da lâmina foliar de um exemplar controle de C. macrophyllum (Figura 3-A) apresenta epiderme unisseriada, com cutícula espessa, estômatos apenas na face abaxial, que a caracteriza como uma folha hipoestomática, apresenta mesofilo dorsiventral, com uma camada de parênquima paliçádico e duas a três camadas de parênquima esponjoso. Apresenta também canais secretores na região mediana do mesofilo do folíolo.

Os danos anatômicos visíveis foram observados na dosagem de 800 g i.a. ha-1 (Figuras 3-G e 3-H), entretanto já na dosagem 25 g i.a. ha-1 (Figura 3-B), observou-se uma alteração na coloração da secreção presente nas cavidades secretoras, essa alteração permaneceu até a dosagem $800 \mathrm{~g}$ i.a. ha-1 . No controle a coloração na cavidade secretora apresenta-se mais translúcida (Figura 3-A), mudando totalmente a cor a partir da dose 25 g i.a. ha ${ }^{-1}$ (Figuras 3-B a 3-G).

Alterações em formatos celulares foram visíveis na dose $800 \mathrm{~g}$ i.a. ha-1 (Figuras 3-G e 3-H), onde as células aparecem totalmente colapsadas, distorcidas, com a coloração alterada, típica de tecido necrosado.

A análise estatística indicou que, quando comparada ao controle, a dose de $800 \mathrm{~g}$ i.a. ha-1 ocasionou uma diferença significativa entre as médias das epidermes adaxial (EAD) e abaxial (EAB) e dos parênquimas paliçádico (PP) e esponjoso (PE) em relação às plantas expostas à maior dose de glifosato (Tabela 2). Nessa dosagem a redução foi de aproximadamente 7\% em EAD, 17,4\% em PP,11,4\% em PE e 11,7\%, em EAB, quando comparados aos tecidos dos controles. Alterações em EAB foram significativas a partir da dosagem 25 g i.a. ha-1 (Tabela 2).

Tabela 2: Morfometria de lâmina foliar de Cenostigma macrophyllum após exposição a diferentes concentrações de glifosato.

\begin{tabular}{lllll}
\hline Glifosato & EAD $(\mu \mathrm{m})^{*}$ & $\mathrm{PP}(\mu \mathrm{m})^{*}$ & $\mathrm{PE}(\mu \mathrm{m})^{*}$ & EAB $(\mu \mathrm{m})^{*}$ \\
$\mathbf{0}$ & $15.94 \mathrm{a}$ & $44.85 \mathrm{ab}$ & $47.66 \mathrm{ab}$ & $15.56 \mathrm{a}$ \\
$\mathbf{2 5}$ & $15.77 \mathrm{ab}$ & $42.51 \mathrm{ab}$ & $50.36 \mathrm{a}$ & $14.73 \mathrm{~b}$ \\
$\mathbf{5 0}$ & $16.11 \mathrm{a}$ & $42.51 \mathrm{ab}$ & $47.03 \mathrm{abc}$ & $14.62 \mathrm{~b}$ \\
$\mathbf{1 0 0}$ & $14.06 \mathrm{c}$ & $41.85 \mathrm{~b}$ & $45.78 \mathrm{abc}$ & $14.33 \mathrm{bc}$ \\
$\mathbf{2 0 0}$ & $15.85 \mathrm{ab}$ & $45.57 \mathrm{a}$ & $46.21 \mathrm{abc}$ & $14.7 \mathrm{~b}$ \\
$\mathbf{4 0 0}$ & $15.33 \mathrm{abc}$ & $44.91 \mathrm{ab}$ & $43.73 \mathrm{bc}$ & $13.37 \mathrm{c}$ \\
$\mathbf{8 0 0}$ & $14.82 \mathrm{bc}$ & $37.05 \mathrm{c}$ & $42.23 \mathrm{c}$ & $13.74 \mathrm{c}$ \\
$\mathbf{C V}(\%)$ & 12.15 & 14.50 & 19.51 & 10.37 \\
\hline
\end{tabular}

${ }^{(*)}$ Significativo a $5 \%$ pelo teste de F. Médias seguidas pela mesma letra nas colunas não diferem entre si a $5 \%$ de probabilidade pelo teste de Tukey. EAD: Epiderme adaxial; PP: Parênquima paliçádico; PE: Parênquima esponjoso; EAB: Epiderme abaxial. 

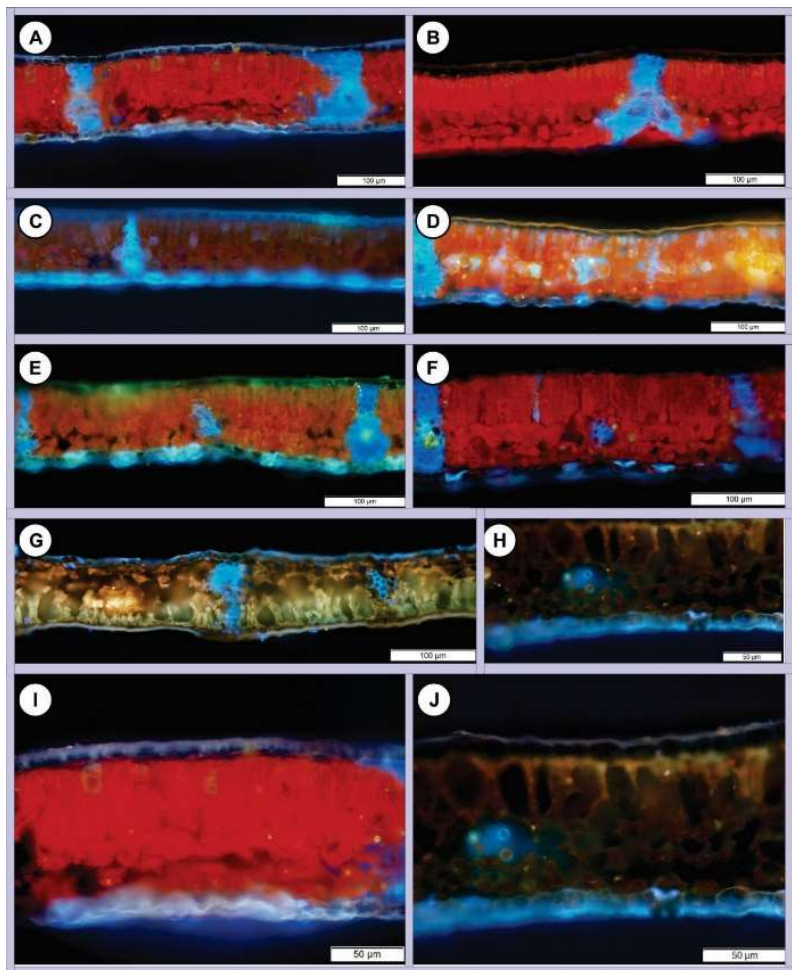

Figura 2: Autofluorescência da clorofila (450-490nm). Cloroplastos dos parênquimas paliçádico e esponjoso emitem fluorescência vermelha típica. A e I: $(0 \mathrm{~g}$ i.a ha' 1); B: (25 g i.a ha $\left.{ }^{-1}\right)$; C: (50 g i.a ha $\left.{ }^{-1}\right)$; D: (100 g i.a ha-1); E: (200 g i.a ha-1); F: (400 g i.a ha $\left.{ }^{-1}\right)$; G, H e J: (800 g i.a ha

$\left.{ }^{1}\right)$. As áreas amarelas representam degradação da clorofila.

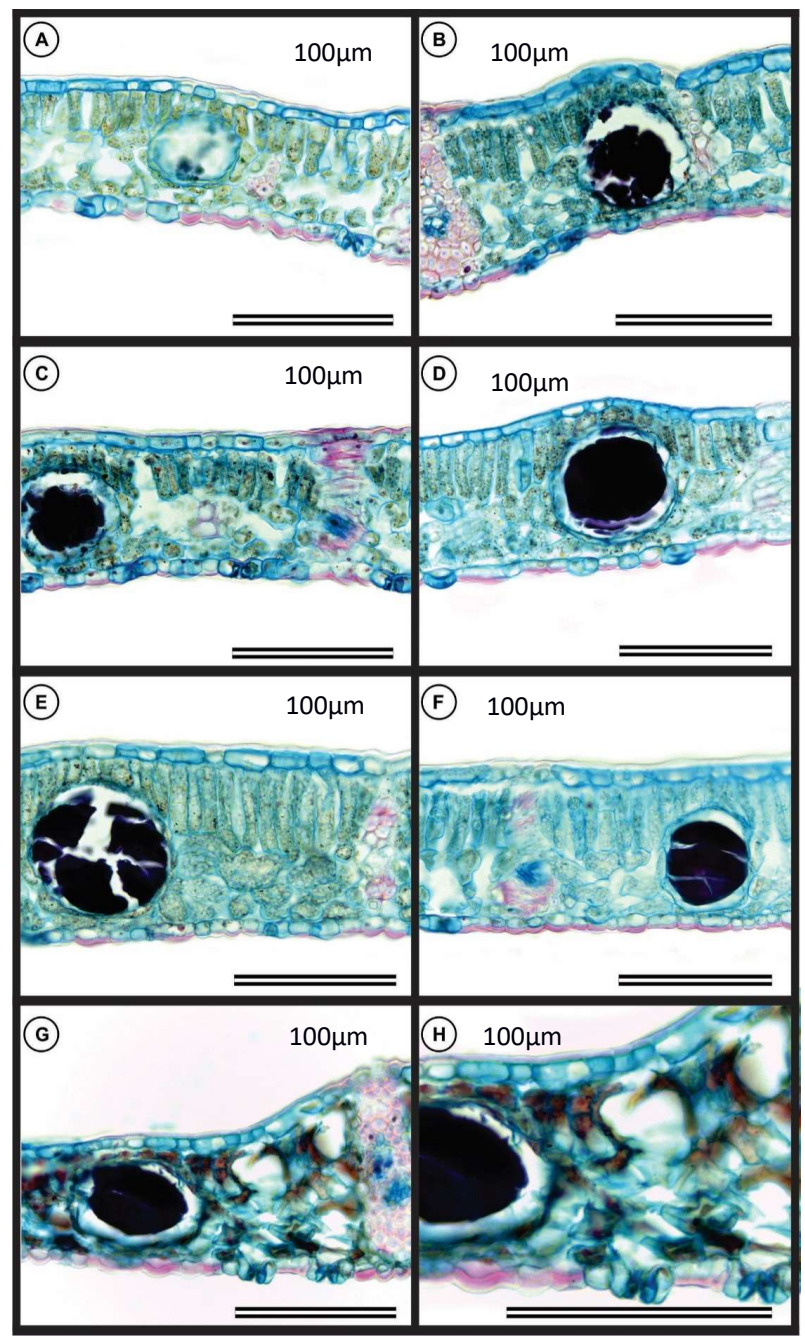

Figura 3: Estrutura da lâmina foliar de Cenostigma macrophyllum em secção transversal (microscopia de luz) no tratamento controle e submetidas à ação do glifosato A-H. A (0 g i.a ha $\left.{ }^{-1}\right)$; B (25 g i.a ha $\left.{ }^{-1}\right)$; C (50 g i.a ha ${ }^{-1}$ ); D (100 g i.a ha-1); E (200 g i.a ha-1); F (400 g i.a ha

$\left.{ }^{1}\right)$; G e H (800 g i.a ha-1 $)$. H Detalhe dos danos em G.

\section{Efeitos do glifosato sobre a morfologia foliar}

Os efeitos do glifosato começaram a ser visíveis a partir da dose $100 \mathrm{~g}$ i.a ha ${ }^{-1}$, onde foi possível perceber a presença de pontos e manchas amareladas, indicando clorose foliar. Na dose $800 \mathrm{~g}$ i.a ha- ${ }^{-1}$, o efeito foi mais intenso, com a presença de manchas marrons indicando necrose foliar. Ainda na dose $800 \mathrm{~g}$ i.a ha-1 ${ }^{-1}$ o glifosato afetou os folíolos que brotaram após a aplicação do herbicida, onde foi possível perceber o formato retorcido dos folíolos jovens.

\section{DISCUSSÃO}

Observou-se uma relação entre o aumento do tempo de exposição ao herbicida com o aumento das doses, que influenciaram na redução nos valores da fotossíntese (A), trocas gasosas $\left(\mathbf{g}_{\mathbf{s}}\right)$ e transpiração $(\mathbf{E})$. Entretanto, o fato de que os prejuízos causados à fotossíntese de plantas de $C$. macrophyllum tenham sido verificados, apenas 216 horas após a aplicação do herbicida, corrobora com Sprankle et al. (1975) indicando que a fotossíntese não é o modo primário de ação do glifosato, ou que o herbicida atua lentamente nos 
processo fotossintéticos.

Uma das possíveis explicações acerca da diminuição dos valores de $\mathbf{A}, \mathbf{g}_{\mathrm{s}}$ e $\mathbf{E}$, é a ação do glifosato na célula estomática. É possível que o glifosato tenha efeito direto sobre as células guarda, provocando o fechamento dos estômatos (YANNICCARI et al., 2012). Yamada et al. (2007) sugerem que as células guarda integram um dos sistemas mais sensíveis ao efeito do glifosato na interrupção do metabolismo celular, pois esse herbicida atua diretamente sobre elas, provocando o fechamento dos estômatos. Isso porque, a camada de cutícula sobre as células guarda é mais fina e, como o glifosato penetra na planta através da epiderme das folhas, provavelmente, os estômatos sejam os primeiros a serem afetados pela ação do herbicida. No presente trabalho, isso pode ter ocorrido, pois a cutícula sobre as células guarda de $C$. macrophyllum é mais fina, o que pode estar relacionado à queda nos valores de trocas gasosas e transpiração que afetou a fotossíntese como um todo.

Com a diminuição da condutância estomática, o mais provável seria a redução na relação $\mathrm{Ci} / \mathrm{Ca}$, visto que o fechamento dos estômatos limita a entrada de $\mathrm{CO}_{2}$, fazendo com que naturalmente haja um consumo do $\mathrm{CO}_{2}$ presente no mesofilo $(\mathrm{Ci})$, diminuindo assim a relação $\mathrm{Ci} / \mathrm{Ca}$. Porém, verificou-se, 288 horas após a aplicação, aumento na relação $\mathrm{Ci} / \mathrm{Ca}$, indicando que houve acúmulo de $\mathrm{CO}_{2}$ na cavidade subestomática, fato que evidencia que o efeito não foi apenas estomático. Alguns autores têm sugerido que a elevação de $\mathrm{Ci}$ pode ser justificada pela baixa condutância difusiva de $\mathrm{CO}_{2}$ do mesofilo (FERNANDES et al., 2015; PEEVA et al., 2009).

Os parâmetros de fluorescência da clorofila $a$ não são bons indicadores de danos em $C$. macrophyllum, pois o glifosato não afetou o FSII. Ralph (2000), ao avaliar a toxidade de herbicidas em Halophila ovalis por meio da fluorescência da clorofila $a$, sugeriu que o glifosato não afeta diretamente o transporte de elétrons do FSII e, portanto, a fluorescência da clorofila a pode ser menos sensível aos efeitos primários deste herbicida. Entretanto, Silva et al. (2014) afirmam que avaliações de fluorescência da clorofila $a$ são bons indicadores de danos causados pelo glifosato em nabo forrageiro. É possível que no presente estudo os primeiros efeitos do glifosato não tenham ocorrido nas reações fotoquímicas primárias reguladas pelo FSII, mas sim no Ciclo de Calvin.

O ciclo de Calvin consiste de três fases: carboxilação, redução e regeneração. A proteína Rubisco (ribulose-1,5-bifosfato carboxilase-oxigenase) está diretamente ligada à primeira fase, ela tem atividade carboxilásica e oxigenásica, embora a afinidade pela carboxilação assegure a ocorrência de fotossíntese mesmo que a concentração de $\mathrm{CO}_{2}$ seja muito menor que a de $\mathrm{O}_{2}$, como ocorre normalmente na natureza. Após a carboxilação, a redução de $\mathrm{CO}_{2}$ a carboidratos está diretamente ligada ao consumo de NADPH e ATP, sintetizados pelas reações luminosas das membranas dos tilacoides. Como não houve danos nos fotossistemas, revelados através das análises de fluorescência da clorofila $a$ em C. macrophyllum, a produção de NADPH e ATP não foi comprometida, entretanto, a concentração de $\mathrm{CO}_{2}$ no mesofilo permaneceu alta, indicando que ele foi pouco assimilado no ciclo de Calvin. A capacidade do tecido foliar para assimilação fotossintética de $\mathrm{CO}_{2}$, depende, em grande parte, do conteúdo de Rubisco, sob concentrações de $\mathrm{CO}_{2}$ baixas a intermediárias, a fotossíntese é limitada pela capacidade de carboxilação da Rubisco. 
É possível que neste estudo tenha ocorrido uma diminuição na atividade da enzima Rubisco, ou mesmo uma diminuição na concentração de Rubisco nas folhas de C. macrophyllum. Chaves (2002), não descarta a possibilidade de efeitos metabólicos como danos à Rubisco, interferirem na fotossíntese, no entanto, ele propõe que o principal fator de redução da fotossíntese seja a menor difusão do $\mathrm{CO}_{2}$, causada tanto pela resistência do mesofilo, como pelo déficit da concentração de $\mathrm{CO}_{2}$ pelo fechamento dos estômatos. Portanto, em C. macrophyllum, as duas possibilidades podem ser consideradas, tanto a diminuição na atividade ou concentração da Rubisco, como o fechamento dos estômatos.

Os dados de rendimento quântico potencial (Fv/Fm) e rendimento quântico efetivo do fotossistema II $\left(\Delta \mathrm{F} / \mathbf{F m}^{\prime}\right)$, bem como a taxa aparente de transporte de elétrons (ETR) e o coeficiente de extinção não fotoquímica (NPQ), também não indicaram danos ao FSII, o que teria certamente comprometido a produção de NADPH e ATP para a redução de $\mathrm{CO}_{2}$ na etapa bioquímica da fotossíntese. Essa observação permite pressupor que, caso os danos observados na fotossíntese estejam relacionados à Rubisco. O problema pode ter ocorrido na primeira fase do Ciclo de Calvin, onde a Rubisco, por efeito do glifosato, não conseguiu realizar a carboxilação. Efeito negativo do glifosato na Rubisco, foi descrito na literatura por Olesen et al. (2010), Servaites et al. (1987) e Yanniccari et al. (2012).

Em C. macrophyllum não foram observados danos em relação à permeabilidade de membranas e ao conteúdo de pigmentos cloroplastídicos, corroborando com Cole (1985), que considerou que o glifosato tem efeito negligível sobre as membranas em determinadas espécies. Portanto, quanto à degradação de membranas, C. macrophyllum pode ser considerada uma planta resistente. Dados contrários foram observados por Silva et al. (2014) e Oliveira (2014) que verificaram efeitos negativos, nesses parâmetros, em plantas de Raphanus sativus e Bowdichia virgilioides, respectivamente. Os danos foram a partir das menores doses do herbicida e progressivos com o aumento das mesmas, após terem sido expostas ao glifosato.

No presente trabalho, foram observadas alterações anatômicas foliares, em plantas expostas ao glifosato, mesmo quando não foram observadas alterações macroscópicas. Tais resultados reforçam a importância dos estudos anatômicos para diagnóstico precoce de injúrias (SOIKKELI, 1981).

Diversos autores, dentre eles Catalá et al. (2013) e Moura et al. (2014) utilizaram observações da emissão de autofluorescência da clorofila, em líquens, no caso dos primeiros autores, e em folhas de árvores nativas, no caso dos segundos, a fim de avaliar respostas após exposição a poluentes. Guidi et al. (1997) afirmam que mudanças na intensidade da emissão de autofluorescência da clorofila podem indicar danos precoces provocados por ozônio. No presente estudo, foi possível perceber alterações na intensidade de emissão de autofluorescência da clorofila $a$, principalmente na maior dose aplicada.

Vários estudos mostram que características como variações na espessura dos tecidos que constituem o mesofilo são importantes na determinação da sensibilidade da planta aos poluentes (BUSSOTTI et al., 2005; EVANS et al., 1996; GEROSA et al., 2003; MACHADO et al., 2013; OLIVEIRA, 2014; PEDROSO et al., 2015; SILVA, 2008). Assim como análises anatômicas de autofluorescência da clorofila, análises dos tecidos foliares, indicaram efeitos deletérios do glifosato, o que mostra a possível utilização dessas avaliações na identificação dos efeitos do glifosato em outras plantas. Fica demonstrada a importância em associar às análises 
fisiológicas, as análises morfoanatômicas, para obtenção de dados mais concisos.

Além da redução dos tecidos, na maior dose, eles ficaram colapsados, com parênquimas paliçádico e esponjoso desorganizados e com coloração típica de necrose. Esse tipo de resposta também foi observada por Machado et al. (2013) ao estudarem os efeitos do glifosato em plantas de Solanum lycocarpum, Kilmeyra lathophyton e Bowdichia virgilioides. Esses autores indicaram que o glifosato pode ser o responsável pela redução nos tecidos foliares, uma vez que a aplicação do herbicida resulta na paralização do crescimento e redução importante dos níveis de aminoácidos aromáticos (fenilanina, tirosina e triptofano), os mesmos verificaram que a epiderme adaxial foi a que apresentou maior redução na espessura. Esse mesmo padrão foi encontrado por Oliveira (2014) em plantas de B. virgilioides sob efeito do glifosato, coincidindo em parte com o presente estudo, com a diferença de que, neste, a epiderme abaxial foi a que apresentou maior sensibilidade ao glifosato, com redução a partir da primeira dose, o que provavelmente contribuiu com danos aos estômatos. Cole et al. (1983) acreditam que essa desregularização resulta na perda de carbonos disponíveis para outras reações celulares da planta.

A folha de C. macrophyllum é hipoestomática. Tendo em vista a redução da espessura da EAB em função do glifosato, pode-se deduzir que os estômatos foram afetados e sofreram efeitos do herbicida, o que corrobora com informações já discutidas sobre o efeito do glifosato nas células guarda, provocando o fechamento dos estômatos. Os dados de condutância estomática e transpiração, confirmam tal observação.

O glifosato tem como principal via de ação a inibição específica da enzima 5-enolpiruvil-chiquimato3-fosfato-sintase (EPSPS), que participa da produção de três aminoácidos essenciais (triptofano, fenilanina e tirosina) (JAWORSKI, 1972; ZABLOTOWICZ et al., 2004). Desde a primeira dose, observou-se uma mudança na coloração do composto presente na cavidade secretora localizada na porção mediana do mesofilo, que passou de translúcida (controle) a um tom bem escuro em todas as demais doses avaliadas. É possível que interferências do glifosato na rota do ácido chiquímico sejam responsáveis pela mudança na produção dos compostos presentes em $C$. macrophyllum. Faz-se necessário um estudo específico da ação do glifosato na produção de tais compostos.

Nos folíolos de C. macrophyllum, foi possível observar clorose a partir da dose $100 \mathrm{~g}$ i.a. ha-1 e necrose na dose $800 \mathrm{~g}$ i.a. ha-1. Além da necrose, plantas expostas à maior dose, apresentaram folhas jovens com aspecto retorcido, Yamada et al. (2007) citam como sintomas comuns observados após a aplicação do glifosato, clorose foliar seguida de necrose, podendo também ocorrer enrugamento ou malformações, especialmente nas áreas de rebrotamento.

\section{CONCLUSÕES}

Neste trabalho, sugere-se que para que uma planta seja considerada resistente, faz-se necessário utilizar um conjunto ampliado de metodologias, uma vez que tradicionalmente, danos causados por glifosato tenham sido estudados utilizando basicamente os parâmetros de trocas gasosas, dados de fluorescência, diminuição do conteúdo de pigmentos cloroplastídicos, degradação de membranas e análises anatômicas em microscopia de luz. A análise da emissão de autofluorescência da clorofila é indicada para que sejam 
observados danos precoces em C. macrophyllum.

Os parâmetros avaliados que indicaram danos em C. macrophyllum foram fotossíntese, trocas gasosas, transpiração, relação entre a concentração interna e externa de $\mathrm{CO}_{2}$, emissão da autofluorescência da clorofila e análises morfoanatômicas. Esses parâmetros podem ser usados como bioindicadores dos efeitos do herbicida utilizando a espécie avaliada, não sendo indicada a avaliação de fluorescência da clorofila a.

\section{REFERÊNCIAS}

AGUIAR, T. V.; SANT'ANNA-SANTOS, B. F.; AZEVEDO, A. A.; FERREIRA, R. S.. Anati Quanti: software de análises quantitativas para estudos em anatomia vegetal. Planta Daninha, Viçosa, v.25, n.4, p.649-659, 2007. Dol: http://doi.org/10.1590/S0100-83582007000400001

BILGER, W.; BJÖRKMAN, O.. Role of the xanthophyll cycle in photoprotection elucidated by measurements of lightinduced absorbance changes, fluorescence and photosynthesis in leaves of Hedera canariensis. Photosyntheses Researche, Stanford, v.25, n.3, p.173-185, 1990. DOI: http://doi.org/10.1007/BF00033159

BILGER, W.; SCHREIBER, U.; BOCK, M.. Determination of the quantum efficiency of photosystem II and of nonphotochemical quenching of chlorophyll fluorescence in the field. Oecologia, Würzburg, v.102, n.4, p.425-432, 1995. DOI: http://doi.org/10.1007/BF00341354

BUSSOTTI, F.; AGATI, G.; DESOTGIU, R.; MATTEINI, P.; TANI, C.. Ozone foliar symptoms in woody plant species assessed with ultrastructural and fluorescence analysis. New Phytologist, Firenze, v.166, n.3, p.941-55, 2005. DOI: http://doi.org/10.1111/j.1469-8137.2005.01385.x

CATALÁ, M.; GASULLA, F.; DEL REAL, A. E. P.; GARCÍA-BREIJO F.; REIG-ARMIÑANA, J.; BARRENO, E.. The organic air pollutant cumene hydroperoxide interferes with NO antioxidant role in rehydrating lichen. Environmental Pollution, Madrid, v.179, p.277-284, 2013. DOI: http://doi.org/10.1016/j.envpol.2013.04.015

CHAVES, M. M.. How plants cope with water stress in the field? Photosynthesis and Growth. Annal of Botany, Lisboa, v.89, n.7, p.907-916, 2002. DOI:

http://doi.org/10.1093/aob/mcf105

COLE, D. J.. Mode of action of glyphosate-a literature analysis. In: GROSSBARD, E.; ATKINSON, D.. The herbicide glyphosate. London: Butterworths Publishers, 1985. p.48-74.

COLE, D. J.; CASELEY, J. C.; DODGE, A. D.. Influence of glyphosate on selected plant process. Weed Research, Oxford, v.23, n.3, p.173-183, 1983. DOI: http://doi.org/10.1111/j.1365-3180.1983.tb00535.x

EHLERINGER, J.. Leaf absorptances of mohave and sonoran desert plants. Oecologia, Salt Lake City, v.49, n.3, p.366-370, 1981. DOI: http://doi.org/10.1007/BF00347600

EVANS, L. S.; ADAMSKI, J. H. I.; RENFRO, J. R.. Relationships between cellular injury, visible injury of leaves, and ozone exposure levels for several dicotyledonous plant species at
Great Smoky Mountains National Park. Environmental Experimental Botany, New York, v.36, n.2, p.229-237, 1996. DOI: http://doi.org/10.1016/0098-8472(96)01002-7

FERNANDES, E. T.; CAIRO, P. A. R.; NOVAES, A. B. Physiological responses of eucalyptus clones grown in a greenhouse under water deficit. Ciência Rural, Santa Maria, v.45, n.1, p29-34, 2015. Dol: http://doi.org/10.1590/0103$8478 \mathrm{cr} 20120152$

GENTY, B.; BRIANTAIS, J.-M.; BAKER, N. R.. The relationship between the quantum yield of photosynthetic electron transport and quenching of chlorophyll fluorescence. Biochimica et Biophysica Acta - Gen. Subj, Colchester, v.990, n.1, p.87-92, 1989. DOI:

http://doi.org/10.1016/S0304-4165(89)80016-9

GERLACH, D.. Botanische Mikrotechnik: Eine Einführung. 3 ed. Stuttegart: Thieme, 1984.

GEROSA, G.; MARZUOLI, R.; BUSSOTTI, F.; PANCRAZI, M.; BALLARIN-DENTI, A.. Ozone sensitivity of Fagus sylvatica and Fraxinus excelsior young trees in relation to leaf structure and foliar ozone uptake. Environmental Pollution, Milan, v.125, n.1, p.91-98, 2003. DOI: http://doi.org/10.1016/S0269-7491(03)00094-0

GUIDI, L.; NALI, C.; CIOMPI, S.; LORENZINI, G.; SOLDATINI, G. F.. The use of chlorophyll fluorescence and leaf gas exchange as methods for studying the different responses to ozone of two bean cultivars. Journal of Experimental Botany, Pisa, v.48, n.308, p,173-179, 1997. DOI:

http://doi.org/10.1093/jxb/48.1.173

HAUPT, A. W.. A gelatin fixative for paraffin sections. Stain Technology, Los Angeles, v.5, n.3, p.97-98, 1930. DOI: http://doi.org/10.3109/10520293009115555

HOAGLAND, D. R.; ARNON, D. I.. The water-culture method for growing plants without soil. California Agricultural Experiment Station, Berkeley, Circular 347, p.1-32, 1950.

JAWORSKI, E.. Mode of action of $\mathrm{N}$ phosphonomethylglycine. Inhibition of aromatic amino acid biosynthsis. J. Agricultural and Food Chemistry, St Louis, v.20, n.6, p.1195-1198, 1972. DOI: http://doi.org/10.1021/jf60184a057

KARNOVSKY, M. J.. A formaldehyde glutaraldehyde fixative of high osmolality for use in electron microscopy. The Journal of Cell Biology, Boston, v.27, n.137, p137-139, 1965.

KRAUS, J. E.; ARDUIN, M.. Manual básico de método em 
morfologia vegetal. Seropedica: Edur, 1997.

KUKI, K. N.; OLIVA, M. A.; GOMES, F. P.; COSTA, A. C.. Avaliação da eficiência do dimetilsulfóxido na extração de pigmentos foliares de Schinus terebenthifolius e Cocos nucifera. In: CONGRESSO BRASILEIRO DE FISIOLOGIA VEGETAL, 10; CONGRESSO LATINO-AMERI- CANO DE FISIOLOGIA VEGETAL, 12. Anais. Recife: SBFV, 2005.

LAISK, A, LORETO, F.. Determining Photosynthetic Parameters from Leaf $\mathrm{CO} 2$ Exchange and Chlorophyll Fluorescence. Plant Physiol., Estonia, v.110, n.3, p.903-912, 1996. DOI: http://doi.org/10.1104/pp.110.3.903

MACHADO, V. M.; SANTOS, J. B.; PEREIRA, I. M.; LARA, R. O.; CABRAL, C. M.; AMARAL, C. S.. Sensitivity of native forest species seedlings to glyphosate. Bioscience Journal, Diamantina, v.29, n.6, p.1941-1951, 2013.

MOKBEL, M. S.; HASHINAGA, F.. Evaluation of the antioxidant activity of extracts from buntan (Citrus grandis Osbeck) fruit tissues. Food Chemistry, Korimoto, v.94, n.4, p.529-534, 2006. DOI: http://doi.org/10.1016/j.foodchem.2004.11.042

MOURA, B. B.; SOUZA, S. R.; ALVES, E. S.. Response of Brazilian native trees to acute ozone dose. Environmental Science and Pollution Research, São Paulo, v.21, n.6, p.4220-4227, 2014. DOI: http://doi.org/10.1007/s11356013-2326-1

OLESEN, C. F.; CEDERGREEN, N.. Glyphosate uncouples gas exchange and chlorophyll fluorescence. Pest Managimente Science, v.66, n.5, p.536-542, 2010. DOI:

http://doi.org/10.1002/ps.1904

OLIVEIRA, A. P. A.. Respostas Fisiológicas e morfoanatômicas de Bowdichia virgilioides Kunth.

(Fabacea) exposta a herbicidas. Dissertação (Mestrado em Ecologia de Ecótonos) - Universidade Federal do Tocantins, Porto Nacional, 2014.

SPRANKLE, P.; MEGGITT, W. F. D. P.. Absorption, Action, and Translocation of Glyphosate. Weed Science, Michigan, v.23, n.6882, p.235-240, 1975. DOI: http://doi.org/https://doi.org/10.1017/S0043174500052930

PEDROSO, A. N. V.; ALVES, E. S.. Temporal dynamics of the cellular events in tobacco leaves exposed in São Paulo, Brazil, indicate oxidative stress by ozone. Environmental Science Pollution Research, São Paulo, v.22, n.9, p.65356545, 2015. DOI: http://doi.org/10.1007/s11356-014-4025-y

PEEVA, V.; CORNIC, G.. Leaf photosynthesis of Haberlea rhodopensis before and during drought. Environmental Experimental Botany, Orsay Cedex, v.65, n.2-3, p.310-318, 2009. DOI: http://doi.org/10.1016/i.envexpbot.2008.09.009

PIMENTEL, C.; SARR, B.; DIOUF, O.; ABBOUD, A. C. D. S.; ROYMACAULEY, H.. Tolerância protoplasmática foliar à seca, em dois genótipos de caupi cultivados em campo. Revista da Universidade Rural, Rio de Janeiro, v.22, n.1, p.7-14, 2002.

QUEIROZ, L. P.. Distribuição das espécies de leguminosae na caatinga. In: ASSOCIAÇÃO PLANTAS DO NORDESTE-APNE/ CENTRO NORDESTINO DE INFORMAÇÕES SOBRE PLANTASCNPI. Anais. Recife: Vegetação e Flora da Caatinga, 2002.
QUEIROZ, L. P.. Leguminosas de Caatinga: espécies com potencial forrageiro. Programa Plantas do Nordeste, Universidade Estadual de Feira de Santana, Royal Botanic Gardens Kew, Associação Plantas do Nordeste, CNPq, Weston Fondation, 1998.

R CORE TEAM. R: A Language and Environment for Statistical Computing. R CORE TEAM, 2015

RALPH, P. J.. Herbicide toxicity of Halophila ovalis assessed by chlorophyll $a$ fluorescence. Aquatic Botany, Sidney, v.66, n.2, p.141-152, 2000. DOI: http://doi.org/10.1016/S03043770(99)00024-8

RASCHER, U.; LIEBIG, M.; LÜTTGE, U.. Evaluation of instant light-response curves of chlorophyll fluorescence parameters obtained with a portable chlorophyll fluorometer on site in the field. Plant, Cell and Environmental, Darmstadt, v.23, n.12, p.1397-1405, 2000. DOI: http://doi.org/10.1046/j.1365-3040.2000.00650.x

RONEN, R.; GALUN, M.. Pigment extraction from lichens with dimethyl sulfoxide (DMSO) and estimation of chlorophyll degradation. Environmental Experimental Botany, Tel Aviv, v.24, n.3, p.239-245, 1984. DOI: http://doi.org/10.1016/0098-8472(84)90004-2

SERVAITES, J. C.; TUCCI, M. A.; GEIGER, D. R.. Glyphosate effects on carbon assimilation, ribulose bisphosphate carboxylase activity, and metabolite levels in sugar beet leaves. Plant Physiology, Dayton, v.85, n.2, p.370-4, 1987. DOI: http://doi.org/10.1104/pp.85.2.370

SILVA, M. F.; SOUZA, L. A. G.; CARREIRA, L.; M. M.. Nomes populares das Leguminosas do Brasil. Manaus: EDUA, 2004

SILVA, F. B.; COSTA, A. C.; RODRIGO, R.; ALVES, P.. Chlorophyll fluorescence as an indicator of cellular damage by glyphosate herbicide in Raphanus sativus L. American Journal of Plants Sciences, Rio Verde, v.5, n.16, p.2509-2519, 2014. DOI: http://doi.org/10.4236/ajps.2014.516265

SILVA, H. R.; SILVA, C. C. M.; NETO, L. B. C.; LOPES, J. A. D.; CITÓ, A. M. D. G. L.; CHAVES, M. H.. Constituintes químicos das cascas do caule de Cenostigma macrophyllum: Ocorrência de colesterol. Química Nova, Teresina, v.30, n.8, p.1877-1881, 2007. DOI: http://doi.org/10.1590/S010040422007000800015

SILVA, K. L. F.. Avaliações de biomarcadores anatômicos e fisiológicos em plantas expostas ao arsênio. Tese (Doutorado em Botânica) - Universidade Federal de Viçosa, Viçosa, 2008.

SOIKKELI, S.. Comparison of cytological injuries in conifer needles from several polluted industrial environments in Finland. Annales Botanic FenniciFinnish Zoological and Botanical Publishing Board, Kuopio, v.18, n.1, p.47-61, 1981.

VAN KOOTEN, O.; SNEL, J. F. H.. The use of chlorophyll fluorescence nomenclature in plant stress physiology. Photosynthesis Research, Wageningen, v.25, n.3, p.147-150, 1990. DOI: http://doi.org/10.1007/BF00033156

VASQUEZ-TELLO, A.; ZUILY-FODIL, Y.; THI, A. T. P.; SILVA, J. B. V.. DAElectrolyte and Pi leakages and soluble sugar content 
as physiological tests for screening resistance to water stress in phaseolus and vigna species. Jounal Experimental Botany, Paris, v.41, n.228, p.827-832, 1989. DOI:

http://doi.org/10.1093/jxb/41.7.827

WARWICK, M. C.; LEWIS, G. P.. A revision of Cenostigma (Leguminosae - Caesalpinioideae - Caesalpinieae), a genus endemic to Brazil. Kew Bulletin, Kew, v.64, n.1, p.135-146, 2009. DOI: http://doi.org/10.1007/s12225-008-9091-1

WELLBURN, A. R.. The spectral determination of chlorophyll a and chlorophyll b, as well as total carotenoids, using various solvents with spectrophotometers of different resolution. Journal of Plant Physiology, Lancaster, v.144, n.3, p.307-313, 1994. DOI: http://doi.org/10.1016/S01761617(11)81192-2
YAMADA, T.; CASTRO, P. R. C.. Efeitos do glyphosate nas plantas: Implicações fisiológicas e agronômicas. Piracicaba: IPNI, 2007.

YANNICCARI, M.; TAMBUSSI, E.; ISTILART, C.; CASTRO, A. M. Glyphosate effects on gas exchange and chlorophyll fluorescence responses of two Lolium perenne L. biotypes with differential herbicide sensitivity. Plant Physiology and Biochemistry, La Plata, v.57, p.210-217, 2012. DOI: http://doi.org/10.1016/i.plaphy.2012.05.027

ZABLOTOWICZ, R. M.; REDDY, K. N.. Impact of Glyphosate on the Brady rhizobium japonicum Symbiosis with GlyphosateResistant Transgenic Soybean: A Minireview. Journal of Environment Souybean, Madson, v.33, n.3, p.825-831, 2004. DOI: $\underline{\text { http://doi.org/10.2134/jeq2004.0825 }}$

A CBPC - Companhia Brasileira de Produção Científica (CNPJ: 11.221.422/0001-03) detém os direitos materiais desta publicação. Os direitos referem-se à publicação do trabalho em qualquer parte do mundo, incluindo os direitos às renovações, expansões e disseminações da contribuição, bem como outros direitos subsidiários. Todos os trabalhos publicados eletronicamente poderão posteriormente ser publicados em coletâneas impressas sob coordenação da Sustenere Publishing, da Companhia Brasileira de Produção Científica e seus parceiros autorizados. Os (as) autores (as) preservam os direitos autorais, mas não têm permissão para a publicação da contribuição em outro meio, impresso ou digital, em português ou em tradução. 